\title{
Effects of Ru Addition on the Superconducting Properties of the Eu-123 System
}

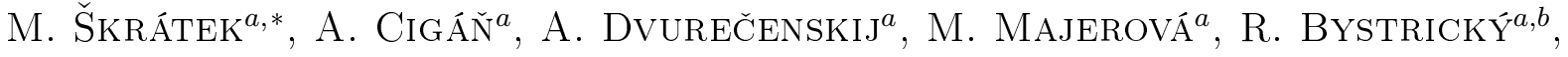 \\ P. BILLIK ${ }^{a}$ AND J. MAŇKA ${ }^{a}$ \\ ${ }^{a}$ Institute of Measurement Science, Slovak Academy of Sciences, Dúbravská cesta 9, 84104 Bratislava, Slovakia \\ ${ }^{b}$ Institute of Inorganic Chemistry, Slovak Academy of Sciences, Dúbravská cesta 9, 84104 Bratislava, Slovakia \\ Effects of the Ru addition on the structural and superconducting properties of the Eu- 123 system were studied. \\ Samples of the nominal composition $\mathrm{EuBa}_{2} \mathrm{Cu}_{3-x} \mathrm{Ru}_{x} \mathrm{O}_{7-\delta}$ with $x$ ranging from 0.0 to 0.7 were prepared by the \\ solid state reaction technique from $\mathrm{Eu}_{2} \mathrm{O}_{3}, \mathrm{BaCO}_{3}, \mathrm{CuO}$ and $\mathrm{RuO}_{2}$ precursors at the temperature of $1050{ }^{\circ} \mathrm{C}$ for \\ $72 \mathrm{~h}$ in flowing oxygen and oxygen-annealed at $580^{\circ} \mathrm{C}$ for $24 \mathrm{~h}$. X-ray diffraction data show the presence of another \\ $\mathrm{Ba}-\mathrm{Eu}-\mathrm{Ru}-\mathrm{O}$ phase, for $x \geq 0.03$, in addition to the main superconducting phase. AC and DC magnetization \\ characteristics were measured by the compensation method using the second-order SQUID gradiometer at $\approx 77 \mathrm{~K}$ \\ and the QD SQUID magnetometer MPMS XL-7 at $20 \mathrm{~K}$. The superconducting properties, $T_{\mathrm{c}}, \Delta T_{\mathrm{c}}$, change only \\ weakly up to $x=0.2$, and magnetization $M(H)$ deteriorates with an increasing Ru content.
}

DOI: $10.12693 /$ APhysPolA.127.225

PACS: 74.72.-h, 74.25.Ha, 75.30.Et, 75.60.-d

\section{Introduction}

The chemical doping is a useful tool for the study of the mechanism of the high- $T_{\mathrm{c}}$ superconductivity in RE123 superconductors, where $\mathrm{RE}$ is $\mathrm{Y}$ or lanthanide. With regard to the role of $\mathrm{Cu}-\mathrm{O}_{2}$ planes, special attention has been paid to substitutions by $\mathrm{M}=\mathrm{Fe}, \mathrm{Co}, \mathrm{Ni}, \mathrm{Mg}, \mathrm{Sc}, \mathrm{Ti}$, $\mathrm{Ge}, \mathrm{Sn}, \mathrm{Pb}, \mathrm{Au}, \mathrm{Ag}$, etc., into copper positions. Mostly, it has been reported that with an increasing content of M-doping atoms $x, T_{\mathrm{c}}$ decreases, namely for a higher substitution content. However, it has been observed that changes of $T_{\mathrm{c}}$ depend not only on the doping level but also on the way of the sample preparation.

Among RE-123 systems, particular attention has been paid to Y-123 and relatively small attention has been paid to $\mathrm{M}=\mathrm{Ru}$. In addition, some inconsistent results were reported for the case of nonmagnetic, e.g., Y-cations or magnetic Gd-cations in RE-123. Shulga et al. in [1] for $\mathrm{YBa}_{2} \mathrm{Cu}_{3-x} \mathrm{Ru}_{x} \mathrm{O}_{7-\delta}$ reported that the presence of a platinum group metal did not decrease $T_{\mathrm{c}}$. For $x=$ 0.4 , they reported the critical temperature $T_{\mathrm{c}}(R)=94 \mathrm{~K}$ and for $x=0.5$ still $T_{\mathrm{c}}(R)=89 \mathrm{~K}$. On the other hand, for the $\mathrm{GdBa}_{2} \mathrm{Cu}_{3-x} \mathrm{Ru}_{x} \mathrm{O}_{7-\delta}$ system, Award et al. [2] reported that the superconductivity had been completely destroyed for $x=0.3$.

\section{Experimental}

We have studied effects of doping of the $\mathrm{Ru}$ ions in the $\mathrm{EuBa}_{2} \mathrm{Cu}_{3-x} \mathrm{Ru}_{x} \mathrm{O}_{7-\delta}$ compound. Samples with the nominal composition deflection $x=$ $0.0,0.01,0.03,0.07,0.1,0.2$, and 0.7 were prepared

\footnotetext{
* corresponding author; e-mail: martin.skratek@savba.sk
}

by a standard solid-state reaction method using commercial $99.99 \%$ purity oxide powders of $\mathrm{Eu}_{2} \mathrm{O}_{3}, \mathrm{CuO}$, and $\mathrm{BaCO}_{3}$. Thereafter, the powders were carefully weighed in appropriate weight amounts and homogenized in air in an agate mortar for 5 min and calcined at $930^{\circ} \mathrm{C}$ for $40 \mathrm{~h}$ in air. The obtained precursors were again homogenized, pressed into pellets (with the diameter of $12 \mathrm{~mm}$ ) and sintered in a horizontal tube furnace in flowing oxygen of $20 \mathrm{ml} / \mathrm{min}$ ) at about $1050^{\circ} \mathrm{C}$ for $72 \mathrm{~h}$, then cooled to $580^{\circ} \mathrm{C}$ and held at this temperature for $24 \mathrm{~h}$ and thereafter cooled in the furnace to room temperature.

We prepared three sets of $\mathrm{EuBa}_{3-x} \mathrm{Ru}_{x} \mathrm{O}_{7-\delta}$ samples. The samples in each set were prepared in one (and the same) thermal cycle. All three sets of the samples show almost identical properties. For example, for $x=0.1$, the values of the critical temperature and $\left(\Delta T_{\mathrm{c}}\right)$ of the corresponding sample in the first, second, and third set represent $88.4 \mathrm{~K}(1.5 \mathrm{~K}), 90.6 \mathrm{~K}(2.0 \mathrm{~K}), 90.7 \mathrm{~K}(1.9 \mathrm{~K})$, respectively. In the paper, we reported results of the second set of the samples, except for the magnetization vs. applied magnetic field dependences, at $20 \mathrm{~K}$, in Fig. 1, which were measured on the samples of the first set only. The results of the detailed study of magnetic properties of $\mathrm{EuBa}_{2} \mathrm{Cu}_{3-x} \mathrm{Ru}_{x} \mathrm{O}_{7-\delta}$ compounds will be published in another paper.

$T_{\mathrm{c}}(R=0)$ was determined by the standard resistance four-point method and the transition width $\Delta T_{\mathrm{c}}$ was characterized by the $10-90 \%$ criterion. The inaccuracy of temperature measurements was less than $0.2 \mathrm{~K}$. The phase composition was studied by X-ray diffraction measurements ( $\mathrm{Cu} K_{\alpha}$ radiation). AC low field magnetization $M_{\mathrm{AC}}$ at $77 \mathrm{~K}$ was measured by a compensation method using the second-order SQUID gradiometer [3] and DC magnetization $M_{\mathrm{DC}}$ at higher field and lower temperature by the Quantum Design SQUID magnetometer MPMS XL-7. 


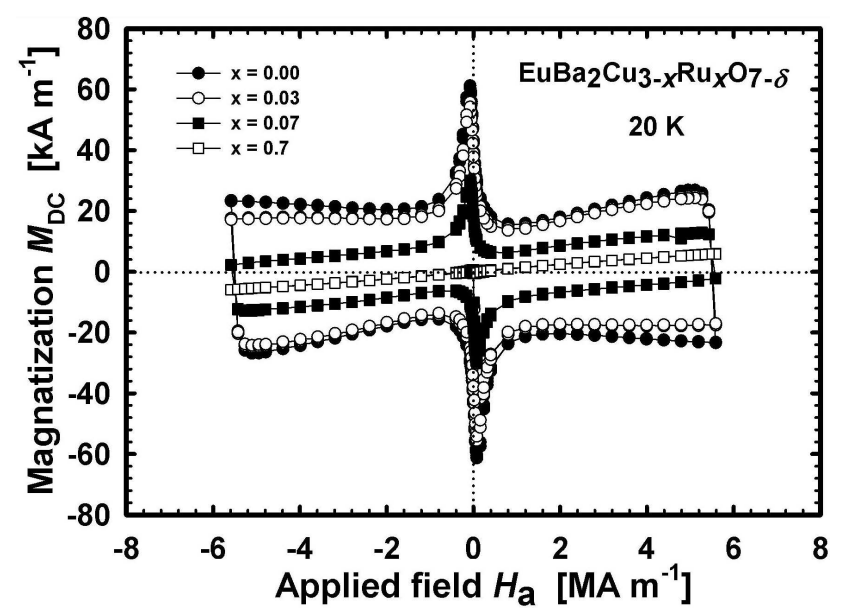

Fig. 1. $M_{\mathrm{DC}}$ vs. $H_{\mathrm{a}}$ dependences at $20 \mathrm{~K}$ and for higher values of $H_{\mathrm{a}}$ of $\mathrm{EuBa}_{2} \mathrm{Cu}_{3-x} \mathrm{Ru}_{x} \mathrm{O}_{7-\delta}$ samples.

\section{Results and discussion}

From X-ray diffraction data, it can be concluded that besides the main superconducting Eu-123 phase, the presence of the excess phase starts evidently for $x \geq$ 0.03. The phase could be identified as the non-metal, non-superconducting $\mathrm{Ba}_{3} \mathrm{EuRu}_{2} \mathrm{O}_{9}$ phase with interesting magnetic properties [4]. Figure 2 and its inset show the effect of the Ru addition on $T_{\mathrm{c}}$ and $\Delta T_{\mathrm{c}}$, respectively.

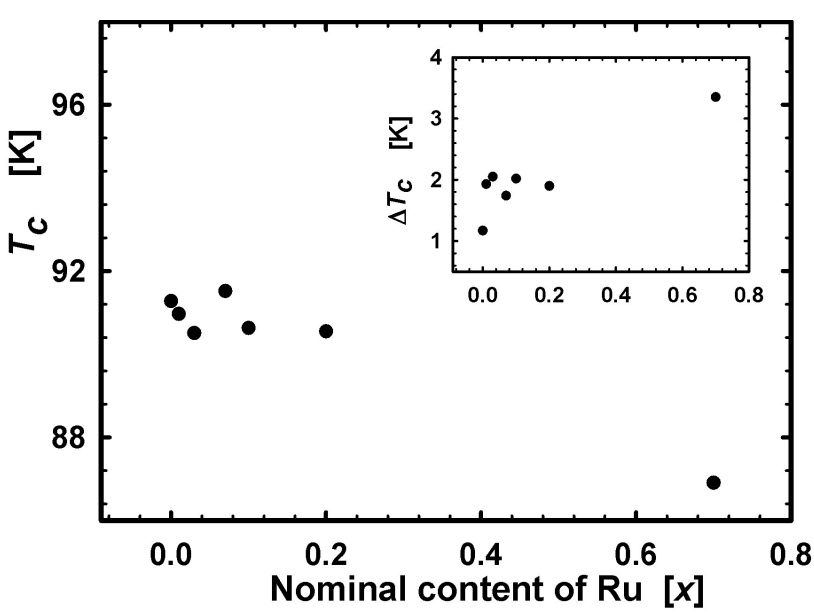

Fig. 2. $T_{\text {c }}$ vs. $x$ of $\mathrm{EuBa}_{2} \mathrm{Cu}_{3-x} \mathrm{Ru}_{x} \mathrm{O}_{7-\delta}$ samples. The insert shows $\Delta T_{\mathrm{c}}$ vs. $x$.

In Fig. 3 the hysteresis curves of the volume magnetization $M_{\mathrm{AC}}$ vs. the applied field $H_{\mathrm{a}}$ for the $\mathrm{EuBa}_{2} \mathrm{Cu}_{3-x} \mathrm{Ru}_{x} \mathrm{O}_{7-\delta}$ samples at $77 \mathrm{~K}$ and relatively low applied field $H_{\mathrm{a}}$ are shown.

The increasing content of $\mathrm{Ru}$ results in decreasing of $M_{\mathrm{AC}}$ and magnetization hysteresis. However, the magnetization curves of the sample with $x=0.7$ show an evident (para)magnetic "tail"- magnetic contribution indicated by the slope of the curve pointing to the first and third quadrants. The hysteresis of the curve could

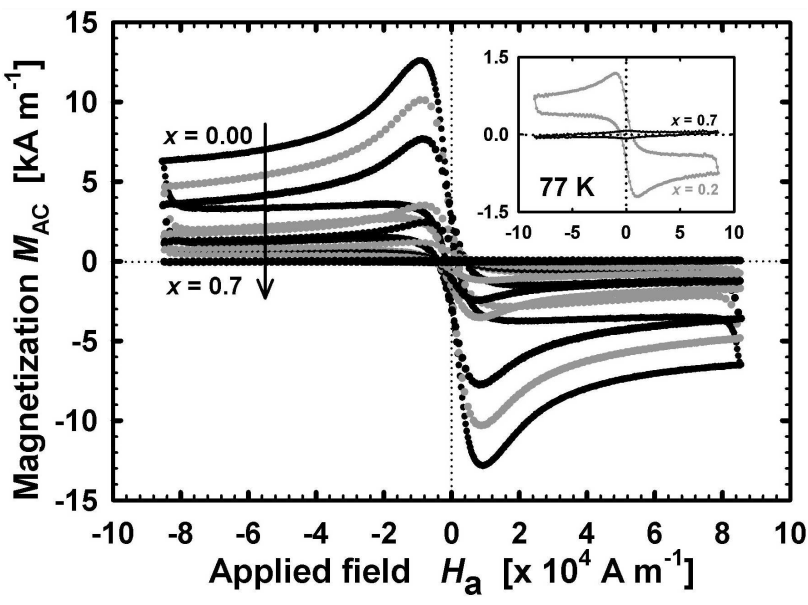

Fig. 3. $M_{\mathrm{AC}}$ vs. $H_{\mathrm{a}}$ of $\mathrm{EuBa}_{2} \mathrm{Cu}_{3-x} \mathrm{Ru}_{x} \mathrm{O}_{7-\delta}$ samples at $77 \mathrm{~K}$ and low magnetic field. Inset is selected view of the hysteresis loops for the samples with $x=0.2$ and 0.7 .

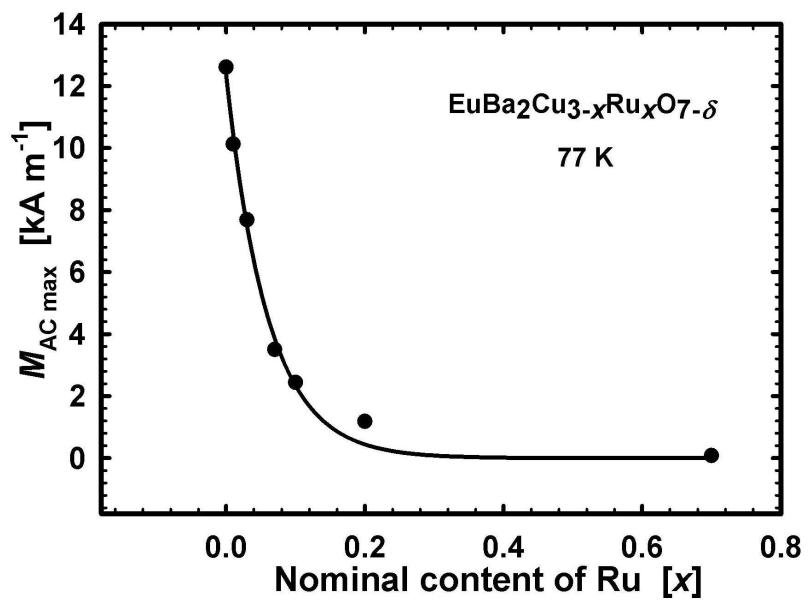

Fig. 4. $M_{\mathrm{AC} \max }$ vs. the nominal content of $\mathrm{Ru}(x)$ for $\mathrm{EuBa}_{2} \mathrm{Cu}_{3-x} \mathrm{Ru}_{x} \mathrm{O}_{7-\delta}$ samples at $77 \mathrm{~K}$.

be ascribed to the superconducting phase. In Fig. 4, a decreasing trend of the maximal value of $M_{\mathrm{AC}},\left(M_{\mathrm{AC} \max }\right)$ with an increase of the $\mathrm{Ru}$ content at $77 \mathrm{~K}$ is documented. The solid line in Fig. 4 is a fit of the measured data by the $y=12.4 \exp (-16.7 x)$ function.

In Fig. 1 the effects of the $\mathrm{Ru}$ addition in $\mathrm{EuBa}_{2} \mathrm{Cu}_{3-x} \mathrm{Ru}_{x} \mathrm{O}_{7-\delta}$ samples at $20 \mathrm{~K}$ and the applied field $H_{\mathrm{a}}$ up to $\approx 5.6 \mathrm{MA} \mathrm{m}^{-1}$ are shown. The magnetization loops with the Ru content $x \leq 0.03$ indicate the so-called second peak effect, while the loops for $x=0.7$ show the magnetic "tail".

The sample with the highest $\mathrm{Ru}$ content shows a strong magnetic contribution that can be ascribed to the $\mathrm{Ba}_{3} \mathrm{EuRu}_{2} \mathrm{O}_{9}$ phase, which competes with the superconducting phase that becomes visible at lower $H_{\mathrm{a}}$ only (see inset of Fig. 5).

The results of the magnetization vs. the applied magnetic field dependences in Fig . 1, 3-5 can be interpreted as a composition of two contributions of the su- 


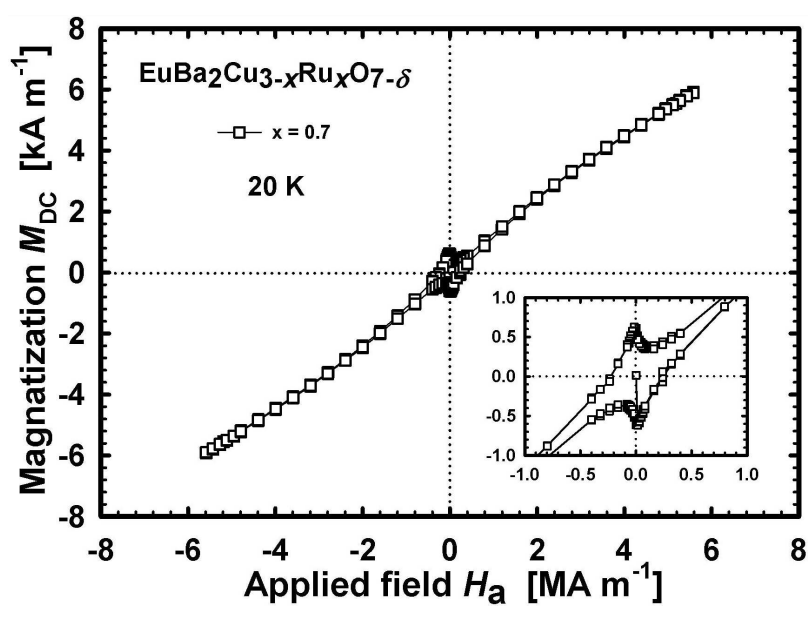

Fig. 5. $\quad M_{\mathrm{DC}}$ vs. $H_{\mathrm{a}}$ of $\mathrm{EuBa}_{2} \mathrm{Cu}_{3-x} \mathrm{Ru}_{x} \mathrm{O}_{7-\delta}$ sample with $x=0.7$ at $20 \mathrm{~K}$. The inset is an enlargement and shows the low-field part where the superconducting contribution dominates in this part of the magnetization curve.

perconducting and paramagnetic components of the Eu123 main phase and magnetic contribution of the excess $\mathrm{Ba}_{3} \mathrm{EuRu}_{2} \mathrm{O}_{9}$ phase. In the first paramagnetic contribution, the Van Vleck paramagnetic contribution of $\mathrm{Eu}^{3+}$ ions must be considered. The magnetic properties of the samples with the high $\mathrm{Ru}$ content strongly affect the secondary $\mathrm{Ba}_{3} \mathrm{EuRu}_{2} \mathrm{O}_{9}$ phase. The indicated effect of the secondary magnetization peak effect could be ascribed to $\mathrm{Eu}^{2+}$ ions that substitute $\mathrm{Ba}^{2+}$ sites in Eu-123, which is in agreement with [5]; and by doing the syntheses of our samples in the oxygen atmosphere.

\section{Conclusions}

The samples with nominal compositions $\mathrm{EuBa}_{2} \mathrm{Cu}_{3-x} \mathrm{Ru}_{x} \mathrm{O}_{7-\delta}$ where $x$ is ranging from 0.0 to 0.7 were prepared by the solid state reaction technique from $\mathrm{Eu}_{2} \mathrm{O}_{3}, \mathrm{BaCO}_{3}, \mathrm{CuO}$, and $\mathrm{RuO}_{2}$ precursors at the temperature of $1050^{\circ} \mathrm{C}$ for $72 \mathrm{~h}$ in flowing oxygen and oxygen-annealed at $580^{\circ} \mathrm{C}$ for $24 \mathrm{~h}$. When increasing the $\mathrm{Ru}$ content, the critical temperature $T_{\mathrm{c}}$ changes slightly only, while still being higher than $90.5 \mathrm{~K}$, and $\Delta T_{\mathrm{c}}$ is still about $2 \mathrm{~K}$ up to $x \leq 0.07$. $\mathrm{X}$-ray diffraction data show the presence of another non-metal $\mathrm{Ba}_{3} \mathrm{EuRu}_{2} \mathrm{O}_{9}$ phase in addition to the main superconducting phase starting from $x=0.03$. Based on that, the $T_{\mathrm{c}}, \Delta T_{\mathrm{c}}$ remain almost unaffected up to $x=0.2$, the magnetization $M(H)$ deteriorates with an increasing $\mathrm{Ru}$ content and the excess $\mathrm{Ba}_{3} \mathrm{EuRu}_{2} \mathrm{O}_{9}$ phase starting from $x=0.03$ suggest that the solution of $\mathrm{Ru}$ in the Eu-123 phase is very limited, if at all.
AC magnetization characteristics, $M_{\mathrm{AC}}$, were measured by a compensation method using the second-order SQUID gradiometer at $\approx 77 \mathrm{~K}$ and $\mathrm{DC}$ magnetization characteristics, $M_{\mathrm{DC}}$, by the QD SQUID magnetometer MPMS XL- 7 at $20 \mathrm{~K}$. The magnetization loops with the Ru content $x \leq 0.03$ indicate the so-called second peak effect and the loops for $x>0.03$ show the magnetization (para)magnetic "tail" at $20 \mathrm{~K}$. The maximum value of the volume magnetization of the samples at $77 \mathrm{~K}$ decreases as the exponential function of the Ru-content $x$.

\section{Acknowledgments}

This research was supported by the Agency of the Ministry of Education of the Slovak Republic for the Structural Funds of the EU, Project Codes 26240220073 and 26240120019, and by the Slovak Research and Development Agency, Grant No. APVV-0125-11.

\section{References}

[1] Yu.M. Shul'ga, E.N. Izakovich, V.I. Rubtsov, B.F. Shklyaruk, Platinum Metals Rev. 37, 86 (1993).

[2] R. Awad, A.I. Abou-Aly, M. Roumié, S.A. Mahmoud, M.M.E. Barakat, Physica C 477, 74 (2012).

[3] V. Zrubec, A. Cigán̆, J. Maňka, Physica C 223, 90 (1994).

[4] Y. Doi, K. Matsuhira, Y. Hinatsu, J. Solid State Chem. 165, 317 (2002).

[5] E. Altin, D.M. Gokhfeld, S. Demirel, E. Oz, F. Kurt, S. Altin, M.E. Yakinci, J. Mater. Sci. Mater. Electron 25, 1466 (2014). 